\title{
UJI FORMULASI Beauveria bassiana ISOLAT LOKAL SEBAGAI PENGENDALI HAYATI HAMA UTAMA KAPAS
}

Oleh :

\author{
IRMA WARDATI, SP, MP , dan DYAH NUNING ERAWATI, SP, MP *)
}

\begin{abstract}
ABSTRAK
Pengembangan pengendali hayati (agens hayati) cendawan entomopatogen $B$. bassiana isolat lokal yang efektif dan efisien sebagai pengendali hama sangat penting untuk dapat meningkatkan produktivitas tanaman kapas dengan tetap memperhatikan kualitas lingkungan hidup yang aman. Sementara bentuk formulasi tepat juga perlu dipertimbangkan, sehingga dapat membantu dalam hal ketersediaan, perbanyakan massal, penyimpanan dan pengaplikasiannya. Penelitian yang dilaksanakan diharapkan dapat menghasilkan: (1) formulasi yang tepat untuk produksi massal cendawan entomopatogen B. bassiana isolat lokal dan (2) Publikasi di Jurnal Ilmiah Nasional Terakreditasi. Metode yang digunakan dalam penelitian adalah Rancangan Acak Kelompok (RAL), selanjutnya data dianalisis dengan uji $\mathrm{F}$ dan dilanjutkan dengan uji DMRT 5\%, dengan parameter pertumbuhan cendawan hasil formulasi dan adanya kontaminan (uji bahan dan produk), kerapatan spora cendawan hasil formulasi (uji viabilitas spora) dan persentase mortalitas serangga uji (uji efikasi di laboratorium). Hasil penelitian adalah formulasi isolat lokal Beauveria bassiana yang diproduksi adalah formulasi cair, pasta dan tepung. Hasil uji kualitas menunjukkan bahwa formulasi cair memberikan hasil terbaik dimana produk formulasi relatif lebih stabil, uji viabilitas tertinggi (kerapatan spora $10^{9}$ spora/ml), uji efikasi relatif tinggi (56,67\% dalam waktu 96 jam), serta waktu kematian $\left(\mathrm{LT}_{50}\right)$ tercepat $(89,72$ jam $)$.
\end{abstract}

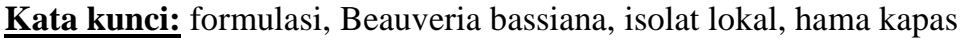

\section{PENDAHULUAN}

Selama ini pengendalian yang dilakukan terhadap hama utama tanaman kapas masih secara kimiawi dengan menggunakan pestisida kimia sintetik, yang menimbulkan banyak dampak negatif. Untuk mengatasi hal ini salah satu alternatif pemecahan yang dapat dilakukan adalah dengan teknik pengendalian hama yang aman bagi lingkungan dan dapat menekan residu kimia pada produk pertanian (pengendalian hayati). Pengendali hayati (agens hayati) yang mempunyai potensi besar sebagai pengendali alami hama tanaman kapas antara lain adalah dari golongan cendawan entomopatogen. Pengembangan agens hayati yang efektif dan efisien sebagai pengendali hama sangat penting untuk dapat meningkatkan produktivitas tanaman kapas dengan tetap memperhatikan kualitas lingkungan hidup yang aman.

Beberapa alasan yang mendasari pemilihan cendawan entomopatogen sebagai pengendali hama adalah kemampuan kapasitas reproduksi yang tinggi, siklus hidup pendek, dapat membentuk spora yang dapat bertahan lama di alam meskipun kondisi lingkungan tidak menguntungkan. Disamping itu, penggunaan cendawan entomopatogen relatif aman, bersifat selektif, kompatibel, relatif mudah diproduksi dan kemungkinan menimbulkan resistensi hama sangat rendah (Widayat dan Rayati, 1993). Hasil penelitian Wardati dan Dyah Nuning Erawati (2013) menunjukkan bahwa isolat lokal cendawan entomopatogen Beauveria bassiana efektif dalam menekan hama pengisap daun kapas (Sundapteryx biguttula) dan ulat daun kapas (Spodoptera litura) hingga $88 \%$ dan $55 \%$.

Sementara ini hal penting yang harus diperhatikan dalam pemanfaatan cendawan entomopatogen adalah bentuk formulasi tepat yang dapat membantu dalam hal ketersediaan, perbanyakan massal, penyimpanan dan pengaplikasiannya. Sehingga penelitian ini dilakukan dengan menggunakan pendekatan yang beorientasi pengembangan penggunaan agens hayati dari golongan cendawan entomopatogen untuk mengendalikan hama utama tanaman kapas, dalam bentuk formulasi yang tepat melalui uji kualitas formulasi (uji bahan dan produk, uji viabilitas spora dan uji efikasi)

Berdasarkan hal tersebut di atas, maka masalah yang dapat dirumuskan di dalam penelitian ini adalah apakah terdapat formulasi cendawan entomopatogen $B$. bassiana isolat lokal yang tepat untuk produksi massal, dalam bentuk pasta, serbuk/tepung dan cair.

Penelitian yang dilaksanakan diharapkan dapat menghasilkan: 
1. Formulasi cendawan entomopatogen $B$. bassiana isolat lokal yang tepat dan efektif untuk produksi massal.

2. Publikasi di Jurnal Ilmiah Nasional Terakreditasi

\section{METODE PENELITIAN}

\section{Rancangan Penelitian}

Penelitian yang direncanakan adalah formulasi isolat lokal agens hayati $B$. bassiana 1 dan 2, dengan tujuan akan diperoleh formulasi yang paling tepat, melalui uji bahan dan produk, uji viabilitas spora dan uji efikasi, dan akan dilaksanakan di Laboratorium Perlindungan Tanaman Politeknik Negeri Jember.

\section{Penelitian Tahun II (dari Rencana 2 Tahun) Tempat dan Waktu Penelitian}

Penelitian tahap II (Tahun II) dilaksanakan di lahan Politeknik Negeri Jember dengan ketinggian 89 meter dpl. Penelitian dilakukan pada bulan Maret sampai dengan bulan Desember 2014.

\section{Bahan dan Alat Penelitian}

Bahan yang digunakan adalah agens hayati cendawan entomopatogen $\quad B$. bassiana isolat lokal yang dihasilkan dari penelitian tahap I, akuades, sukrosa, polypropionic acid, TEA, glyserol, tween-80, TiO2, talkum, tepung singkong, sekam padi, Na-Alginat, urea, ekstrak khamir, KNO3, MgSO4, tetracyclin.

Alat yang digunakan adalah autoclave, laminar air flow, neraca analitis, erlenmeyer, tabung reaksi, cawan petri, jarum ose, tabung reaksi, shaker, penangas air, mikropipet, hand counter, haemocytometer, gelas ukur, magnetic stirer, kompor, kuas, mikroskop, dan pinset, alat tulis, gelas ukur, timbangan, hand counter, knapsack sprayer, alat pengering.

\section{Metode Penelitian}

Penelitian disusun berdasar Rancangan Acak Lengkap (RAL) faktor tunggal dengan 5 (lima) ulangan. Model linier untuk Rancangan Acak Lengkap adalah (Gomes dan Gomes, 1995):

$Y_{i j}=\mu+\tau_{i}+\varepsilon_{i j}$, yaitu:

$Y_{i j}$ : pengamatan pada perlakuan ke-i dan ulangan ke-j

$\mu \quad$ : nilai rata-rata populasi

$\tau_{i} \quad: \quad$ pengaruh perlakuan ke-i

$\varepsilon_{i j} \quad$ : komponen random yang bekerja pada plot perlakuan ke-i dan ulangan ke-j

Faktor tunggal berupa formulasi cendawan entomopatogen $B$. bassiana isolat lokal, yaitu:

1. B. bassiana formulasi pasta (F1)
2. B. bassiana formulasi serbuk/tepung (F2)

3. B. bassiana formulasi cair (F3)

4. Kontrol (F0)

Selanjutnya, analisis data dalam penelitian ini menggunakan F-Test 5\% dengan uji lanjutan Duncan's Multipple Range Test (DMRT) pada taraf signifikansi 5\% (taraf kepercayaan 95\%).

Tahap Pelaksanaan Penelitian

Perbanyakan dan Formulasi Cendawan $B$. bassiana Isolat Lokal

Pembuatan biang biakan (seed culture)

Membuat biang biakan dalam bentuk cair dengan volume disesuaikan dengan kebutuhan, yaitu $10 \%$ dari volume total media untuk produksi biomassa spora atau konidia. Komposisi media (dalam erlenmeyer) disterilkan dalam autoklaf pada suhu $121^{\circ} \mathrm{C}$ dengan tekanan 1 bar, setelah dingin selanjutnya diinokulasi dengan isolat cendawan dari cawan petri atau tabung reaksi. Kemudian diinkubasikan selama 3 hari pada alat penggojok dengan kecepatan 130 strok/menit, suhu $30^{\circ} \mathrm{C}$.

\section{Produksi biomassa spora/konidia}

Cara produksi biomassa spora/konidia sama dengan pembuatan biang biakan, hanya saja dalam volume yang leboih besar, yaitu 50 liter.

\section{Pembuatan produk dan formulasi}

a. Formulasi pasta

Setelah proses perbanyakan biomassa spora/konidia selesai, cairan bersama biomassa dikeluarkan ke dalam wadah tabung pencampur berpengaduk dengan menggunakan pompa transfer atau pompa sirkulasi. Selanjutnya ditambahkan bahanbahan formula sukrosa, polypropionic acid, TEA, glyserol, tween-80, $\mathrm{TiO} 2$ dan akuades.

b. Formulasi serbuk/tepung

Biomassa hasil perbanyakan dipisahkan terlebih dahulu dengan cairan menggunakan alat pemisah, kemudian ditambahkan bahan-bahan pengisi matrik: glyserol, Na-Alginat, urea, akuades, talkum, tepung singkong, sukrosa, sekam padi.

c. Formulasi cair

Biomassa hasil perbanyakan dimasukkan ke dalam media produksi yang mengandung glukosa, KNO3, MgSO4 dan ekatrak khamir, sekitar 5-10\% dari volume total. Selanjutnya diinkubasikan dengan menggunakan bioreaktor atau alat penggojok, pada suhu $25-30^{\circ} \mathrm{C}$, selama 5-7 hari, pada putaran 100 strok/menit.

\section{Pengujian Kualitas Formulasi}

a. Uji bahan dan produk 
Bahan produk hasil formulasi dilarutkan/diencerkan dalam akuades, selanjutnya ditumbuhkan dalam media agar. Kemudian diamati mikroorganisme yang tumbuh dan kemungkinan adanya kontaminan.

b. Uji viabilitas spora

Bahan produk hasil formulasi dilarutkan/diencerkan dalam akuades, selanjutnya dilakukan penghitungan kerapatan sporanya.

c. Uji efikasi pada hama utama kapas secara in vitro

Menggunakan Rancangan Acak Kelompok Lengkap(RAL), dengan 4 (empat) perlakuan dan 5 (lima) ulangan.

\section{Parameter Pengamatan}

Parameter-parameter yang diamati pada penelitian tahap I adalah:

1. Pertumbuhan cendawan hasil formulasi pada media agar, serta adanya kontaminan.

2. Kerapatan spora cendawan hasil formulasi dengan haemocytometer dengan menggunakan rumus:

Kerapatan spora $=\frac{\mathrm{t}}{\mathrm{n} \times 0,25} \times 10^{6}$

$\mathrm{t}=$ jumlah kotak yang berisi spora

$\mathrm{d}=$ faktor pengenceran

$\mathrm{n}=$ jumlah kotak yang diamati

3. Persentase mortalitas serangga uji yaitu menghitung jumlah serangga yang mati pada 24, 48, 72 dan 96 jam setelah perlakuan. Mortalitas serangga uji (\%) dikoreksi dengan rumus Abbot, yaitu :

Kematian serangga uji (\%)

$$
=\frac{\mathrm{A}-\mathrm{B}}{100-\mathrm{B}} \times 100 \%
$$

$\mathrm{A}=$ Persentase kematian tiap perlakuan

$\mathrm{B}=$ Persentase kematian kontrol

\section{Hasil dan Pembahasan \\ Pembuatan Produk dan Formulasi Isolat Lokal Beauveria bassiana}

Terdapat 3 (tiga) macam formulasi isolat lokal B.bassiana yang dilaksanakan dalam penelitian, yaitu formulasi cair, pasta dan serbuk/tepung. Tahapan proses pembuatan formulasi ini meliputi kegiatan-kegiatan:

1. Formulasi Cair

Formulasi cair diperoleh dengan mengambil biang biakan (seed culture) agens hayati $B$. bassiana, selanjutnya ditambahkan dengan larutan glycerol 5\% untuk menjaga kestabilan hidup biomassa spora. Selanjutnya disimpan dalam wadah, pada suhu ruangan.

2. Formulasi Pasta.

Formulasi pasta dibuat dengan mencampurkan bahan-bahan, antara lain: biomassa spora, akuades, talkum, tepung singkong, dedak padi, sukrosa, glycerol, CMC, urea dan TiO2. Bahan-bahan dicampur dan diaduk hingga rata dan membentuk formulasi pasta, selanjunya disimpan pada suhu ruangan. Talkum dan dedak padi merupakan bahan pembawa, sedangkan tepung singkong dan CMC berfungsi untuk perekat dan mempermudah proses pelarutan ketika akan diaplikasikan. Selanjutnya sukrosa dan urea berperan sebagai bahan makanan atau nutrisi bagi agens hayati, sedangkan $\mathrm{TiO} 2$ berfungsi melindungi agens hayati $B$. bassiana dari sinar ultra violet pada saat aplikasi di lapang.

3. Formulasi Serbuk/Tepung

Formulasi serbuk/tepung merupakan proses selanjutnya dari bentuk pasta, yaitu dengan cara bahan yang sudah berbentuk pasta selanjutnya dioven dengan suhu $50^{\circ} \mathrm{C}$ selama kurang lebih 72 jam (3 hari). Tujuan pengovenan adalah mengurangi kadar air hingga $12 \%$, dengan suhu yang tidak sampai mematikan spora agens hayati $B$. bassiana.

Berdasarkan proses produksi ketiga formulasi menunjukkan bahwa yang paling sederhana adalah formulasi cair, sedangkan yang paling rumit adalah formulasi tepung/serbuk. Dari hasil produksi ketiga formulasi terlihat bahwa formulasi cair cenderung lebih stabil dari segi warna, aroma dan kenampakan, dimana warnanya tidak mengalami perubahan mulai awal pembuatan, aroma juga tetap seperti aroma media perbanyakannya yaitu ekstrak kentang dan gula, sedangkan kenampakan tidak ada perubahan yaitu tetap terlihat koloni miselium B.bassiana pada bagian atas media (Gambar 1). 


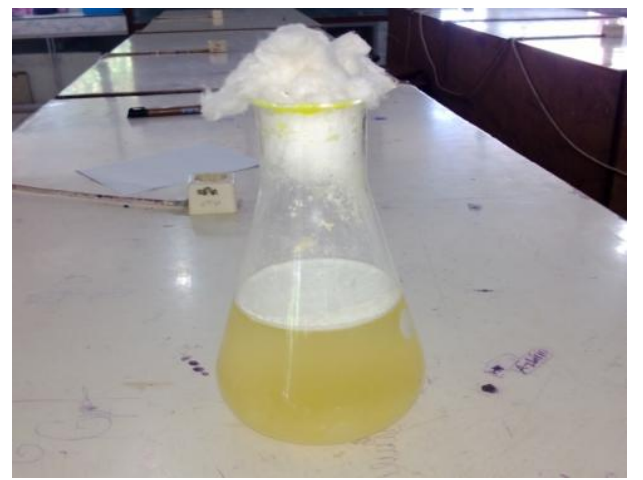

Gambar 1. Formulasi Cair Isolat Lokal $B$. Bassiana

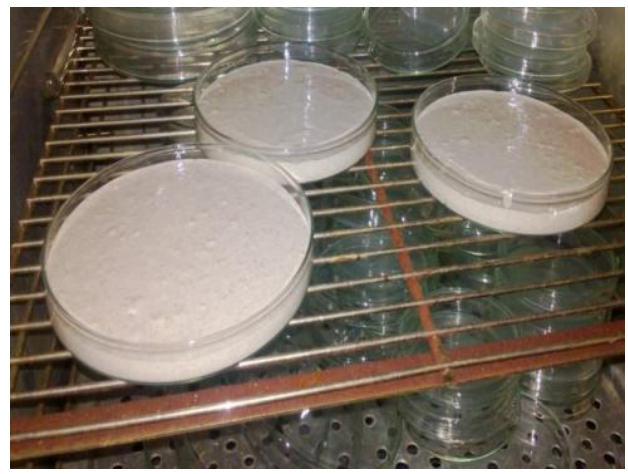

Gambar 2. Formulasi Pasta Isolat Lokal $B$. bassiana

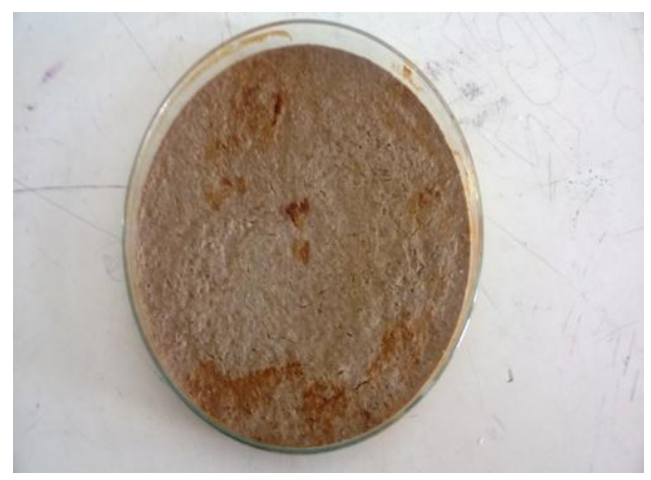

Gambar 3. Formulasi Tepung Isolat Lokal $B$. bassiana
Pada formulasi pasta kestabilan tidak berlangsung lama, dimana pada hari ke 5 (lima) antara padatan dan cairan tidak tercampur sempurna dan terlihat terpisah, sedangkan dari segi aroma mengeluarkan aroma yang menyengat (Gambar 2). Formulasi tepung/serbuk kestabilannya cukup baik, tetapi terjadi perubahan warna ketika proses formulasinya karena terdapat proses pengovenan yang membuat warna menjadi agak kecoklatan, sedangkan dari segi aroma tetap dan tidak mengeluarkan aroma menyengat (Gambar 3)

\section{Uji Kualitas Produk Formulasi Isolat Lokal Beauveria bassiana Uji Bahan dan Produk}

Uji bahan dan produk dilakukan dengan cara produk hasil formulasi dilarutkan/diencerkan dalam akuades, selanjutnya ditumbuhkan dalam media agar. Kemudian diamati mikroorganisme yang tumbuh dan kemungkinan adanya kontaminan. Hasil pengamatan pada awal pengujian menunjukkan bahwa terdapat kontaminasi pada media agar oleh mikroorganisme lain seperti cendawan dan bakteri, sehingga perlu dilakukan pemurniankembali. Selanjutnya untuk mengantisipasi hal ini perlu sterilisasi bahan dan alat yang lebih baik.

Miselium B. bassiana yang tumbuh pada media agar padat berwarna putih seperti kapas, seperti yang dinyatakan oleh Raharjo (1998) bahwa pertumbuhan B. bassiana dalam media berbentuk koloni putih seperti kapas. Konidiofor yang fertil bercabang secara zig zag dan pada bagian ujungnya terbentuk spora (konidia). Konidia bersel satu, berbentuk bulat sampai oval, hialin, berukuran 2-3 mikron. Hifa $B$. bassiana hialin dalam koloni yang berwarna putih (Gambar 4). 



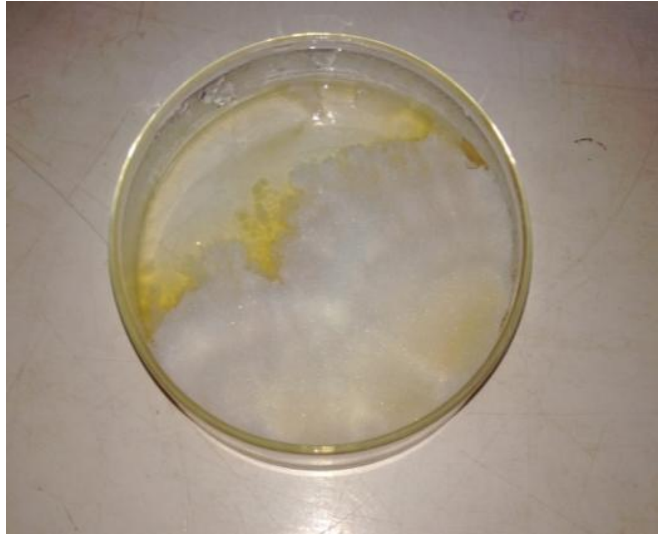

Gambar 4 Miselium B.bassiana pada Media Agar Padat

\section{Uji Viabilitas Spora}

Uji viabilitas spora dilakukan dengan menghitung kerapatan spora pada masing-masing formulasi pada 1 (satu) hari setelah (hst) pembuatan formulasi, 14 hst dan 28 hst, dengan cara mengencerkan agens hayati beserta medianya 100 gram dalam $100 \mathrm{ml}$ akuades, mengaduknya hingga tercampur rata dan selanjutnya diteteskan pada alat haemocytometer, serta dihitung jumlah sporanya di bawah mikroskop.

Hasil penghitungan kerapatan spora awal (1 hst) dari masing-masing formulasi adalah sama, yaitu $10^{9}$ spora $/ \mathrm{ml}$. Kerapatan spora pada penghitungan 14 hst menunjukkan bahwa untuk formulasi cair adalah $1,86.10^{9} \mathrm{spora} / \mathrm{ml}$, formulasi pasta $2,4.10^{8} \mathrm{spora} / \mathrm{ml}$ dan formulasi tepung sebesar 2,74.10 $\quad$ spora $/ \mathrm{ml}$. Sedangkan penghitungan spora pada 28 hst menunjukkan hasil kerapatan spora formulasi cair sebesar $1,2.10^{9}$ spora/ml, formulasi pasta $1,4.10^{8} \mathrm{spora} / \mathrm{ml}$ dan formulasi tepung/serbuk adalah $1,15.10^{8} \mathrm{spora} / \mathrm{ml}$.

Kerapatan spora pada formulasi cair cenderung lebih stabil jika dibandingkan dengan formulasi pasta dan tepung/serbuk. Hal ini menunjukkan bahwa formulasi cair relatif lebih bisa mempertahankan keberadaan spora $B$. bassiana, karena didugaformulasi cair tidak terlalu banyak tahapan proses produksi dan bahan yang ditambahkan sebagaimana pada formulasi

pasta dan tepung, sehingga kerapatan spora masih bisa dipertahankan lebih lama. Hal ini sesuai dengan pendapat Roberto and W.R. Donald (1990) dan Eyal, et.al. (1994) bahwa Beauveria bassiana memiliki kelemahan pada kestabilan konidia atau blastoporanya ketika diformulasikan.

\section{Uji Efikasi Produk Formulasi Isolat Lokal Beauveria bassiana}

Uji efikasi produk formulasi dilakukan dengan mengaplikasikan formulasi cair, pasta dan tepung/serbuk pada larva Spodoptera litura instar tiga sebagai larva uji. Hasil analisis persentase mortalitas larva uji disajikan pada Tabel 1.

\begin{tabular}{|c|c|c|c|c|c|c|c|}
\hline \multirow[t]{2}{*}{ PERLAKUAN } & \multicolumn{7}{|c|}{$\begin{array}{l}\text { PERSEN MORTALITAS LARVA UJI PADA JAM } \\
\text { KE- }\end{array}$} \\
\hline & 24 & 48 & & 72 & & 96 & \\
\hline Cair & 0,00 & 9,33 & ns & 32,00 & A & 56,67 & a \\
\hline Pasta & 0,00 & 5,33 & ns & 20,67 & B & 42,67 & $\mathrm{~b}$ \\
\hline Tepung/Serbuk & 0,00 & 5,33 & ns & 30,67 & A & 54,00 & a \\
\hline Kontrol & 0,00 & 0,00 & ns & 0,00 & C & 0,00 & $\mathrm{c}$ \\
\hline
\end{tabular}

Tabel 1. Hasil Uji Efikasi Formulasi terhadap Larva Uji (Spodoptera litura).

Angka yang diikuti oleh huruf yang sama pada satu kolom menunjukkan tidak signifikan berdasarkan hasil DMRT pada taraf 5\%.

Efektivitas berbagai formulasi terhadap persentase mortalistas serangga uji belum menunjukkan adanya larva yang mati, hal ini diduga karena cendawan B. Bassiana

masih membutuhkan proses penetrasi ke dalam tubuh larva. Pada hari ke dua (48 jam setelah aplikasi) sudah terjadi kematian pada larva uji meskipun masih rendah berkisar antara 5,33\% hingga 9,33\%, sedangkan hasil aplikasi berbagai formulasi menunjukkan hasil yang tidak signifikan. Selanjutnya pada hari ke tiga (72 jam) dan ke empat (96 jam), menunjukkan persentase kematian larva yang cukup tinggi. Efektivitas formulasi cair dan tepung/serbuk memperlihatkan hasil yang berbeda tidak nyata, dan berbeda nyata dengan formulasi pasta serta kontrol, sedangkan formulasi pasta berbeda nyata dengan kontrol, dimana pada kontrol (tanpa aplikasi $B$. bassiana) tidak terdapat larva yang mati hingga jam ke 96.

Hal ini diduga berhubungan dengan kestabilan formulasi pada kenampakan, warna dan aroma, dimana formulasi pasta relatif kurang stabil dibandingkan dengan formulasi cair maupun tepung/serbuk. Selain itu diduga hal ini mempengaruhi efektivitas dari cendawan $B$. bassiana dalam membunuh larva uji, seperti yang dikemukakan oleh Wahyudi (2008), 
bahwa formula cendawan entomopatogen yang disimpan dalam waktu tertentu akan mengalami penurunan viabilitas dan kemampuan dalam membunuh larva serangga.

Waktu kematian serangga uji pada umumnya dinyatakan dengan nilai $\mathrm{LT}_{50}$ (Lethal Time 50), yaitu waktu yang diperlukan oleh agens hayati untuk mengakibatkan mortalitas serangga uji sebesar $50 \%$. Nilai LT $_{50}$ mengindikasikan kecepatan kerja agens hayati (Prijono, 1988). Waktu kematian yang dibutuhkan oleh masingmasing formulasi dalam menekan larva uji dapat dilihat pada Tabel 2. Nilai $\mathrm{LT}_{50}$ berbagai formulasi terhadap larva uji menunjukkan hasil bahwa formulasi cair memberikan waktu tercepat dalam menekan 50\% larva uji yaitu 89,72 jam, diikuti formulasi tepung/serbuk yaitu 91,64 jam dan formulasi pasta yaitu 114, 81 jam.

Tabel 2. Waktu Kematian (Lethal Time) Berbagai Formulasi terhadap Larva Uji

$\begin{array}{ll}\text { PERLAKUAN } & \text { WAKTU KEMATIAN (LETHAL } / \mathrm{LT}_{50}(\mathrm{JAM})\end{array}$

\begin{tabular}{lr}
\hline Cair & 89,72 \\
Pasta & 114,81 \\
Tepung/Serbuk & 91,64 \\
\hline
\end{tabular}

Hasil analisis Probit $\mathrm{LT}_{50}$ dari masing-masing formulasi terhadap larva uji menghasilkan persamaan garis regresi seperti terlihat pada Tabel 3.

Tabel 3. Persamaan Garis Regresi Hasil Pendugaan Hubungan Log Waktu Kematian dengan Probit Kematian

\begin{tabular}{lc}
\hline \multicolumn{1}{c}{ PERLAKUAN } & PERSAMAAN \\
& GARIS REGRESI \\
\hline Cair & $\mathrm{y}=1,2991+1,8951 \mathrm{x}$ \\
Pasta & $\mathrm{y}=-1,6112+3,2099 \mathrm{x}$ \\
Tepung/Serbuk & $\mathrm{y}=-3,1643+4,1610 \mathrm{x}$ \\
\hline
\end{tabular}

Berdasarkan persamaan garis regresi di atas diperoleh grafik pendugaan hubungan log waktu kematian dengan probit kematian, seperti terlihat pada Gambar 5.

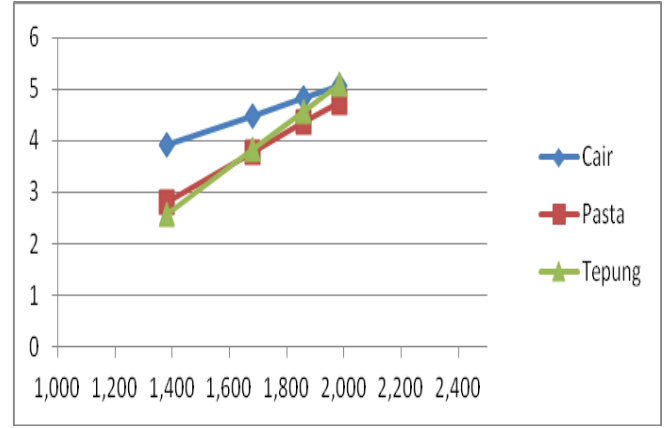

Gambar 5 Grafik Pendugaan Hubungan Log Waktu Kematian dengan Probit Kematian dari Berbagai Formulasi terhadap Larva Uji

Gambar 5 memperlihatkan formulasi cair memiliki waktu kematian tercepat, diikuti oleh formulasi tepung dan pasta. Persamaan garis regresi yang dihasilkan dari analisis probit waktu kematian $\left(\mathrm{LT}_{50}\right)$ menggambarkan hubungan antara waktu yang diperlukan oleh perlakuan berbagai agens hayati untuk menyebabkan kematian larva uji sebesar 50\%. Angka kematian sebesar 50\% menunjukkan bahwa formulasi $B$. bassiana mampu menekan larva uji, semakin cepat waktu yang diperlukan maka formulasi $B$. bassiana semakin efektif dalam menekan larva uji (Prijono, 1988). Dalam hal ini formulasi cair B. bassiana paling efektif dalam menekan larva uji dibandingkan formulasi tepung dan pasta.

\section{KESIMPULAN DAN SARAN}

\section{Kesimpulan}

Berdasarkan hasil dan pembahasan maka dapat disimpulkan bahwa formulasi isolat lokal Beauveria bassiana yang diproduksi adalah formulasi cair, pasta dan tepung. Hasil uji kualitas menunjukkan bahwa formulasi cair memberikan hasil terbaik dimana produk formulasi relatif lebih stabil, uji viabilitas tertinggi (kerapatan spora $10^{9}$ spora/ml), uji efikasi relatif tinggi $(56,67 \%$ dalam waktu 96 jam), serta waktu kematian $\left(\mathrm{LT}_{50}\right)$ tercepat $(89,72$ jam).

\section{Saran}

Berdasarkan penelitian yang telah dilaksanakan, maka disarankan untuk meneliti lebih lanjut dalam hal mencari komposisi yang paling tepat terutama untuk formulasi pasta dan tepung/serbuk, agar diperoleh produk formulasi yang baik dan stabil dalam hal penyimpanan maupun aplikasi. 


\section{DAFTAR PUSTAKA}

Eyal, J., J.F. Walter, L. Osborne and Zdenek, L. 1994. Methode For Production and Use of Phatogenic Fungal Preparation For Pest Control. US. Patent No.5,360,607. Nov.1,1994

Gomes, K.A. dan A.A. Gomes. 1995. Prosedur Statistik untuk Penelitian Pertanian (terjemahan oleh E. Sjamsudin dan J.S. Baharsjah). UI-Press. Jakarta.

Mukaromah, F. 2013. Formulasi Agens Pengandali Hayati (APH) Golongan Bakteri Menurut Ahli Bakteri. Balai Besar Perbenihan dan Proteksi Tanaman Perkebunan. Surabaya Ditjenbun Deptan. http://ditjenbun.deptan.go.id/bbpptpsurabay a/. Diakses tanggal 7 Januari 2014).

Prijono, D. 1988. Pengujian Indektisida. Jurusan Hama dan Penyakit Tumbuhan Fakultas Pertanian Instiut Pertanioan Bogor

Raharjo, K. 1998. Penggunaan Jamur Metarhizium anisopliae dan Beauveria bassiana untuk Mengendalikan Beberapa Jenis Hama. Kumpulan Makalah Gelar Teknologi Spesifik Lokasi. Karawang, 5-9 Oktober 1998. hal 36-40.

Roberto, M.P. and W.R. Donald. 1990. Dray Mycelium Praparation of Entomophatogenic Fungi Metarhizium anisopliae and Beauveria bassiana. $J$. Invertebrate Phatology. 56,39-46. Academic Press,Inc.

Suwahyono, U. dan P. Wahyudi. 2008. Produksi dan Formulasi Bioinsektisida dari Propagul Aktif Jamur Beauveria bassiana. Jurnal Teknologi Lingkungan. Vol. 9. No. 1. Hal. 89-91. Jakarta.

Wahyudi, P. 2008. Enkapsulasi Propagul Jamur Entomopatogen Beauveria bassiana Menggunakan Alginat dan Pati Jagung sebagai Produk Mikoinsektisida. Jurnal Ilmu Kefarmasian Indonesia, 6(2), 51-56.

Wardati, I., D.N. Erawati dan C. Triwidiarto. 2011. Patogenisitas Bakteri, Jamur dan Nematoda Entomopatogen terhadap Hama Utama Tanaman Kapas (Gossypium hirsutum). Laporan Penelitian Hibah Bersaing DP2M Dikti. (belum dipublikasikan).

Wardati dan D.N. Erawati (2013). Efektivitas Cendawan Entomopatogen Beauveria bassiana Isolat Lokal terhadap Hama Utama Tanaman Kapas (Gossypium hirsutum L.). Laporan Penelitian Hibah Bersaing DP2M Dikti (belum dipublikasikan). 